\title{
INFLUÊNCIA DA ALTURA DE PASTEJO DE AZEVÉM E AVEIA EM ATRIBUTOS FÍSICOS DE UM LATOSSOLO VERMELHO DISTROFÉRRICO, APÓS SETE ANOS SOB INTEGRAÇÃO LAVOURA-PECUÁRIA ${ }^{(1)}$
}

\author{
Wagner Henrique Moreira ${ }^{(2)}$, Cássio Antonio Tormena ${ }^{(3)}$, Edner Betioli Junior ${ }^{(2)}$, \\ Leonardo Pim Petean ${ }^{(4)} \&$ Sérgio José Alves ${ }^{(5)}$
}

\begin{abstract}
RESUMO
A pressão exercida pelos cascos dos animais pode ocasionar a compactação superficial do solo em sistema integração lavoura-pecuária (SILP), com reflexos na qualidade física dele. A hipótese do trabalho foi de que o pisoteio dos animais em decorrência do pastejo das culturas de aveia e azevém num Latossolo Vermelho distroférrico com SILP sob plantio direto degrada a qualidade física do solo. $\mathrm{O}$ objetivo deste trabalho foi avaliar o efeito de diferentes alturas de pastejo na densidade do solo (Ds), na porosidade total (PT), na macro e microporosidade, na porosidade no domínio dos macroporos (POMAC) e da matriz do solo (POMAT), na capacidade de aeração do solo (CATSOLO) e da matriz do solo (CAMAT), na capacidade de armazenamento de água e ar e no intervalo hídrico ótimo (IHO) de um Latossolo Vermelho distroférrico, após sete anos sob SILP. A área estudada, localizada no município de Campo Mourão, PR, foi manejada em SILP com semeadura direta de soja/milho no verão e consórcio de aveia+azevém no inverno, utilizado como forragem para o pastejo pelos animais. Os tratamentos consistiram em quatro alturas de pastejo $(7,14,21$ e $28 \mathrm{~cm})$ e um tratamento-controle (testemunha). Em cada tratamento, foram coletadas 36 amostras com estrutura indeformada, nas profundidades de 0,0-7,5 e 7,5-15,0 cm, para determinação dos atributos físicos do solo. A hipótese do trabalho foi confirmada, pois a aeração foi reduzida com intensificação do pastejo. Após sete anos de SILP, a altura de pastejo de $7 \mathrm{~cm}$ resultou em redução da qualidade física do solo, indicada pela Ds, PT, POMAT e quantidade de amostras com Ds > densidade do solo crítica (Dsc) na
\end{abstract}

(1) Recebido para publicação em 27 de agosto de 2013 e aprovado em 2 de abril de 2014.

(2) Discentes do Programa de Pós-Graduação em Agronomia da Universidade Estadual de Maringá - UEM. Av. Colombo, 5790. CEP 87020-900 Maringá (PR). E-mail: wh.moreira@hotmail.com, betioli.jr@gmail.com

(3) Professor Associado, Departamento de Agronomia, UEM. Bolsista do CNPq. E-mail: catormena@uem.br

(4) Professor do curso de Agronomia, Faculdade Integrado de Campo Mourão, Rodovia BR 158, km 207. CEP $87300-970$ Campo Mourão (PR). E-mail: leonardopim@hotmail.com

(5) Pesquisador, Instituto Agronômico do Paraná (IAPAR). Caixa Postal 481. CEP 86001-970 Londrina (PR). E-mail: sja@iapar.br 
profundidade de $0,0-7,5 \mathrm{~cm}$; e pela macroporosidade, CAMAT, CATSOLO e capacidade de armazenamento de ar, na profundidade de 7,5-15,0 cm. Com o aumento da $\mathrm{Ds}$, ocorreram valores restritivos de aeração e resistência à penetração no IHO em todos os tratamentos e nas duas camadas, com efeito mais pronunciado na camada de $0,0-7,5 \mathrm{~cm}$.

Termos de indexação: aeração, estrutura do solo, intervalo hídrico ótimo, pisoteio animal, resistência do solo à penetração.

\title{
SUMMARY: INFLUENCE OF THE GRAZING HEIGHT OF RYEGRASS AND OAT ON THE PHYSICAL PROPERTIES OF AN OXISOL AFTER SEVEN YEARS OF CROP-LIVESTOCK SYSTEM
}

\begin{abstract}
The pressure applied by animal hooves can lead to soil surface compaction in a croplivestock system (CLIS), with effects on soil physical quality. The hypothesis of this study was that the trampling of animals as a result of grazing on oat and ryegrass crops in a Latossolo Vermelho distroférrico (Oxisol) under no-tillage in a CLIS degrades soil physical quality. The aim of this study was to evaluate the effect of different grazing heights on soil bulk density (BD), total porosity (TP), macro- and microporosity, porosity in the soil macropore domain (PORp) and in the soil matrix domain (PORm), total soil aeration capacity (ACt) and soil matrix capacity (ACm), soil water and air storage capacity, and the least limiting water range (LLWR) of an Oxisol after seven years under CLIS. The area under study, located in Campo Mourão, PR, Brazil, was managed in a CLIS with a no-till system of soybean/corn in the summer and oat+ryegrass in the winter, which was used as forage for animal grazing. The treatments consisted of four grazing heights $(7,14,21$ and $28 \mathrm{~cm}$ ) and a control (control). In each treatment, 36 undisturbed samples were collected at the 0.0-7.5 and 7.5-15.0 cm depths for determination of soil physical properties. The hypothesis of the study was confirmed as aeration was compromised from intensification of grazing. After seven years of CLIS, the grazing height of $7 \mathrm{~cm}$ resulted in reduction of soil physical quality as indicated by BD, TP, $P O R m$, and number of samples with $B D>$ the critical $B D(B D c)$ in the 0.0-7.5 cm depth; and by macroporosity, ACm, Act, and air storage capacity in the 7,5-15.0 cm depth. With the increase of $B D$, restrictive values of aeration and resistance to penetration in the LLWR were found in all treatments and in the two layers, with the most pronounced effect in the 0.0-7.5 cm layer.

Index terms: aeration, soil structure, least limiting water range, animal trampling, soil resistance to penetration.
\end{abstract}

\section{INTRODUÇÃO}

O sistema integração lavoura-pecuária (SILP) é um sistema de produção que possui como um dos principais preceitos a diversificação planejada das atividades agrícolas e pecuárias dentro da propriedade rural. Desse planejamento, espera-se um incremento da qualidade do solo em razão da melhoria de suas propriedades químicas, físicas e biológicas. Contudo, em relação aos atributos físicos, o manejo em SILP sob longo período ainda carece de maior entendimento, principalmente no que se refere à manutenção (Flores et al., 2007; Conte et al., 2011) ou à redução da qualidade física do solo em decorrência do pisoteio animal associado à pressão de pastejo (Petean et al., 2010; Fidalski et al., 2013). A pressão exercida pelos cascos dos animais pode ocasionar a compactação superficial do solo em razão do aumento da densidade do solo (Ds) e da redução da porosidade do solo (Twerdoff et al., 1999; Giarola et al., 2007), comprometendo a produtividade de grãos e da pastagem.
A Ds e a porosidade do solo são as propriedades físicas mais utilizadas em estudos dos impactos causados pelo SILP sobre o solo (Marchão et al., 2007; Lanzanova et al., 2007; Carneiro et al., 2009; Spera et al., 2010). A porosidade livre de água entre 0,10-0,15 $\mathrm{m}^{3} \mathrm{~m}^{-3}$ é considerada capaz de promover adequadas trocas gasosas entre o solo e a atmosfera, sendo amplamente utilizada como referência para o satisfatório crescimento e desenvolvimento do sistema radicular das plantas (Grable \& Siemer, 1968; Mueller et al., 2008; Reynolds et al., 2009). Em relação à Ds, o estabelecimento de um valor satisfatório, para ser utilizado como referência nos estudos que avaliam a qualidade física dos solos, não pode ser seguramente realizado, visto que esse atributo apresenta grande variabilidade em razão da classe textural e do teor de matéria orgânica dos solos (Dias Junior \& Miranda, 2000).

Estudos evidenciam que a Ds e a porosidade podem capturar os efeitos do manejo. Bono et al. (2013) apresentaram a ocorrência de diferenças significativas 
na Ds em SILP com Panicum maximum. Marchão et al. (2007) e Carneiro et al. (2009) obtiveram diferenças da macroporosidade entre SILP e área de mata nativa no cerrado; contudo, a Ds e a porosidade podem não apresentar sensibilidade suficiente para mensurar as alterações físicas decorrentes do SILP. Moreira et al. (2012) observaram que a Ds e a porosidade de aeração não apresentaram diferenças na avaliação de diferentes alturas de pastejo em SILP, tendo a resistência do solo à penetração $(\mathrm{RP})$ retratado os efeitos dos tratamentos. Em experimento envolvendo seis sistemas de produção em integração lavoura-pecuária, Spera et al. (2010) realizaram avaliações da macroporosidade do solo aos seis, oito e 10 anos após a implantação do sistema e não encontraram diferenças significativas na camada de 0,0-5,0 cm, em quatro sistemas. Nesse contexto, o uso de indicadores que retratam processos físicos que acontecem na interface solo-raiz é determinante para uma avaliação mais minunciosa do impacto do manejo na qualidade física do solo.

Os indicadores de qualidade física do solo são expressões diretas ou indiretas do volume de poros e, ou, da funcionalidade dos poros (Reynolds et al., 2009), dentre os quais se incluem: porosidade total (PT), porosidade de aeração, capacidade de armazenamento de água e, ou, ar, permeabilidade do solo ao ar, condutividade hidraúlica do solo saturado, intervalo hídrico ótimo (IHO), entre outros. Para avaliação conjunta de atributos físicos envolvidos diretamente com o desenvolvimento das plantas, como aeração, $\mathrm{RP}$ e retenção de água, o IHO (Tormena et al., 2007) tem sido utilizado em estudos de SILP (Petean et al., 2010; Calonego \& Rosolem, 2011; Fidalski et al., 2013). O IHO corresponde à faixa de teor de água $(\theta)$ do solo em que as raízes das plantas encontram mínimas restrições para o crescimento e a obtenção de água e ar, fundamentais para o desenvolvimento das plantas. De modo geral, quanto menor o IHO, maior a probabilidade de ocorrência de limitações físicas para o crescimento das raízes no solo (Silva \& Kay, 1997).

Em SILP, um fator que pode contribuir para a compactação do solo é a pressão de pastejo, resultante da relação entre o peso animal e a massa de forragem disponível. O manejo de uma adequada taxa de lotação animal tem efeito direto sobre a pressão de pastejo, que por sua vez determina a intensidade das alterações no sistema poroso do solo. A hipótese deste trabalho foi de que o pisoteio dos animais em decorrência do pastejo das culturas de aveia e azevém num Latossolo Vermelho distroférrico com SILP sob plantio direto degrada a qualidade física do solo. O objetivo do trabalho foi avaliar o efeito de diferentes alturas de pastejo na Ds, na PT, na macro e microporosidade, na porosidade no domínio dos macroporos (POMAC) e da matriz do solo (POMAT), na capacidade de aeração do solo (CATSOLO) e da matriz do solo (CAMAT), na capacidade de armazenamento de água e ar e no IHO de um Latossolo Vermelho distroférrico, após sete anos sob SILP.

\section{MATERIAL E MÉTODOS}

O experimento foi conduzido no município de Campo Mourão, Paraná, situado a $24^{\circ} 02^{\prime}$ de latitude sul e $52^{\circ} 22^{\prime}$ de longitude oeste. O solo foi um Latossolo Vermelho distroférrico (Embrapa, 2006). A análise granulométrica na camada de 0,0-20,0 cm apresentou valores de 870,92 e $38 \mathrm{~g} \mathrm{~kg}^{-1}$ de argila, silte e areia, respectivamente. Nessa região, o tipo climático dominante, segundo a classificação de Köppen, é o Cfa (subtropical úmido mesotérmico), caracterizado por temperatura média anual entre 20 e $21{ }^{\circ} \mathrm{C}$ e precipitação pluvial entre $1.600 \mathrm{e}$ $1.800 \mathrm{~mm}$.

O experimento foi implantado em 2002 em uma área de 8 ha, anteriormente utilizada por 12 anos em sistema de plantio direto. A área em SILP é cultivada em semeadura direta de soja (Glycine $\max$ L.) ou milho (Zea mays L.) no verão, com ciclo entre outubro e março, e consórcio de aveia (Avena strigosa Schreb) com azevém (Lolium multiflorum Lam.) no inverno, com ciclo entre maio e outubro; essas foram utilizadas como forragem para o pastejo pelos animais. A semeadura das culturas de verão foi realizada utilizando sulcadores revolvendo as linhas para deposição de fertilizantes a 10,0-12,0 cm de profundidade e disco duplo para a deposição das sementes no solo entre $3,0-5,0 \mathrm{~cm}$. As forrageiras de inverno foram semeadas com semeadora de discos no espaçamento de $17,0 \mathrm{~cm}$ nas entrelinhas.

Os tratamentos foram compostos por quatro alturas de manejo das culturas de aveia e azevém: altura de pastejo de $7 \mathrm{~cm}$ com lotação de 2,44 unidades animal (UA), num piquete com área de 1,02 ha; altura de pastejo de $14 \mathrm{~cm}$ com lotação de 2,61 UA, num piquete com área de 1,60 ha; altura de pastejo de $21 \mathrm{~cm}$ com lotação de 2,25 UA, num piquete com área de $2,16 \mathrm{ha}$; altura de pastejo de $28 \mathrm{~cm}$ com lotação de 1,82 UA, num piquete com área de 3,30 ha; e controle (testemunha) sem pastejo com área de 0,08 ha. Foi utilizado o método de pastejo contínuo com lotação animal intermitente, put and take (Mott \& Lucas, 1952). Em cada unidade experimental permaneceram dois animais testers e um número variável de animais reguladores, utilizados de forma a se manterem as diferentes alturas da pastagem em cada tratamento. Os tratamentos foram delimitados com cerca elétrica e durante o período de pastejo a altura da pastagem foi monitorada semanalmente durante o período de cerca de 120 dias.

Em outubro de 2009, com sete anos de implantação do experimento e após a retirada dos animais sob pastejo de aveia e azevém, foram coletadas 36 amostras de solo com estrutura indeformada em cada tratamento e profundidade $(0,0-7,5$ e $7,5-15,0 \mathrm{~cm})$, utilizando-se cilindros com $5,0 \mathrm{~cm}$ de altura e diâmetro. Após a saturação das amostras, essas foram pesadas e submetidas aos potenciais de $-1,-6$ e $-10 \mathrm{kPa}$, usando uma mesa de tensão similar à descrita por 
Ball \& Hunter (1988), para determinar macro e microporosidade, POMAC, POMAT, CATSOLO, CAMAT, capacidade de armazenamento de água e ar. Ao atingir o equilíbrio, indicado pela ausência de drenagem de água, as amostras foram novamente pesadas.

Após as determinações anteriormente citadas, foi feita a determinação da curva de retenção de água (CRA), de acordo com o procedimento descrito por Silva et al. (1994). As amostras de cada tratamento e profundidade foram divididas em 12 grupos de três amostras, que foram submetidas aos potenciais de -2 , $-4,-6,-8,-10 \mathrm{kPa}$ numa mesa de tensão, conforme Ball \& Hunter (1988), e de -30, -50, -70, -100, -200, -400 e - $1.500 \mathrm{kPa}$, utilizando pressões aplicadas em câmaras com placas porosas, conforme Klute (1986). Após atingir o equilíbrio em cada potencial aplicado nas placas porosas, as amostras foram pesadas e, em seguida, foi determinada a RP usando o equipamento e os procedimentos descritos em Tormena et al. (1999). Posteriormente, as amostras foram secas em estufa a $\pm 105^{\circ} \mathrm{C}$, por $24 \mathrm{~h}$, para definir a massa de sólidos e a massa de água no solo. Determinou-se a Ds pela razão entre a massa de sólidos e o volume do cilindro (Grossman \& Reinsch, 2002). O $\theta$ foi obtido pelo produto do teor de água em base de massa com a razão da Ds por densidade da água.

Para quantificar o IHO, foi necessária a descrição matemática da curva de resistência do solo à penetração (CRS) e da CRA. A CRA, expressa pela relação entre $\theta$ e o potencial da água no solo ( $\Psi)$, foi descrita matematicamente por meio de uma função não linear (Equação 1), incorporando a variação da Ds entre as amostras quando significativa, conforme Leão et al. (2005):

$$
\theta=(a+b \mathrm{Ds}) \Psi^{c}
$$

em que $\theta$ : teor de água do solo $\left(\mathrm{m}^{3} \mathrm{~m}^{-3}\right) ; D s$ : densidade do solo $\left(\mathrm{kg} \mathrm{dm}^{-3}\right) ; \Psi$ : potencial da água no solo $(\mathrm{kPa})$; e $a, b$ e $c$ : coeficientes obtidos no ajuste do modelo aos dados de $\theta(\Psi)$.

A relação funcional entre a $\mathrm{RP}, \theta$ e Ds foi utilizada para definir a CRS, a qual foi modelada utilizando uma função não linear proposta por Busscher (1990), descrita na equação 2 :

$$
\mathrm{RP}=d \mathrm{Ds}^{e} \theta^{f}
$$

em que RP: resistência do solo à penetração $(\mathrm{MPa}) ; \theta$ : teor de água do solo $\left(\mathrm{m}^{3} \mathrm{~m}^{-3}\right)$; Ds: densidade do solo $\left(\mathrm{kg} \mathrm{dm}^{-3}\right)$; e $d$, e e $f:$ coeficientes obtidos no ajuste do modelo aos dados.

O IHO foi determinado adotando-se os procedimentos descritos em Silva et al. (1994) e Tormena et al. (1999). Os valores de $\theta$ associados com $\Psi, \mathrm{RP}$ e porosidade de aeração limitantes ao crescimento das plantas foram: a capacidade de campo $\left(\theta_{\mathrm{CC}}\right)$ ou teor de água no $\Psi$ de $-10 \mathrm{kPa}$ (Reichardt, 1988); o ponto de murchamento permanente $\left(\theta_{\mathrm{PMP}}\right)$ ou teor de água no $\Psi$ de $-1500 \mathrm{kPa}$ (Savage et al., 1996); e o teor de água no solo em que a porosidade de aeração $\left(\theta_{\mathrm{PA}}\right)$ é de $0,10 \mathrm{~m}^{3} \mathrm{~m}^{-3}$ (Grable $\&$ Siemer, 1968). Para a RP, foi adotado o valor crítico de 3,5 MPa, conforme Ehlers et al. (1983), considerando que em sistema plantio direto (SPD) a macroporosidade é constituída por bioporos contínuos, os quais possibilitam a adoção de maior valor de RP, uma vez que evidências experimentais indicam que as raízes usam esses bioporos como rotas alternativas para seu crescimento numa matrix mais densa, comum em SPD consolidado. Recentemente o trabalho de Moraes et al. (2014) corroboram a adoção de $\mathrm{RP}=3.5 \mathrm{MPa}$, como referência para solos argilosos sob SPD no Estado do Paraná. Os valores de $\theta_{\mathrm{CC}} \mathrm{e}$ $\theta_{\mathrm{PMP}}$ foram obtidos utilizando a CRA; e os valores do teor de água, em que a $\mathrm{RP}\left(\theta_{\mathrm{RP}}\right)$ atinge $3,5 \mathrm{MPa}$, foram obtidos isolando o $\theta$ na equação 2 . $O$ valor de $\theta_{\mathrm{PA}}$ foi obtido por [(1 - Ds/Dp) - 0,1]. A densidade de partículas $(\mathrm{Dp})$ foi estimada pelo método do balão volumétrico, conforme Embrapa (1997); utilizou-se um valor de $2,85 \mathrm{~kg} \mathrm{dm}^{-3}$, que corresponde à média de 33 amostras coletadas aleatoriamente na área experimental.

A PT foi obtida pela relação PT $=1-(\mathrm{Ds} / \mathrm{Dp}) . \mathrm{O} \theta$ após equilíbrio no $\Psi$ de $-6 \mathrm{kPa}$ foi considerado equivalente à microporosidade do solo; e a macroporosidade foi calculada pela diferença entre a PT e o $\theta$, no $\Psi$ de $-6 \mathrm{kPa}$ (Embrapa, 1997). Outros indicadores de qualidade física do solo foram calculados, conforme Reynolds et al. (2002): porosidade no domínio dos macroporos do solo (POMAC), obtida pelo $\theta$ saturado subtraído do $\theta$ no $\Psi$ de $-1 \mathrm{kPa}$; porosidade no domínio da matriz do solo (POMAT), obtida pelo $\theta$ no $\Psi$ de $-1 \mathrm{kPa}$; capacidade de ar do solo (CATSOLO), obtida pelo $\theta$ na saturação subtraída do $\theta$ no $\Psi$ de $-10 \mathrm{kPa}$; capacidade de ar da matriz do solo (CAMAT), obtida pelo $\theta$ no $\Psi$ de - $1 \mathrm{kPa}$ subtraído do $\theta$ no $\Psi$ de $-10 \mathrm{kPa}$; capacidade de armazenamento de água obtida pela razão entre capacidade de campo e PT (adimensional), sendo o valor considerado ideal de 0,66; e a capacidade de armazenamento de ar obtida pela razão entre CATSOLO e PT (adimensional), sendo o valor considerado ideal de 0,34 . O $\theta$ equivalente à capacidade de campo foi considerado aquele no $\Psi$ de $-10 \mathrm{kPa}$.

Os ajustes dos dados à CRA e CRS foram feitos empregando o software SAS Institute (SAS, 2002). O efeito da profundidade foi testado com o proc glm do SAS, e a comparação estatística entre os coeficientes ajustados para as CRAs de cada posição seguiram os procedimentos descritos em Regazzi (2003), utilizando o teste da razão de verossimilhança $(p<0,05)$. As comparações dos atributos físicos entre as posições de amostragem foram feitas utilizando o intervalo de confiança da média $(p<0,05)$, conforme Payton et al. (2000). Quando não há sobreposição dos limites superior e inferior do intervalo de confiança, considerase que há diferença significativa. 


\section{RESULTADOS E DISCUSSÃO}

$\mathrm{Na}$ profundidade de $0,0-7,5 \mathrm{~cm}$, a $\mathrm{Ds}$ dos tratamentos com alturas de pastejo equivalentes a 7 e $14 \mathrm{~cm}$ foi superior àquela de $21 \mathrm{~cm}$, corroborando Petean et al. (2010). Esse resultado, associado ao fato de os tratamentos $21 \mathrm{~cm}, 28 \mathrm{~cm}$ e testemunha não serem estatisticamente diferentes, sugere que se pode intensificar o pastejo até a altura de $21 \mathrm{~cm}$ sem comprometer a qualidade física do solo. A Ds no tratamento sem pastejo (testemunha) não apresentou diferenças em relação aos tratamentos com diferentes intensidades de pastejo, denotado pela sobreposição dos limites do intervalo de confiança da média (Figura 1). A ausência de diferenças entre a testemunha e os outros tratamentos corrobora os resultados obtidos por Moreira et al. (2012) na mesma área de estudo, indicando que nos tratamentos onde houve pastejo pode existir equilíbrio entre a degradação causada pelo pastejo e a resiliência física associada ao desenvolvimento do sistema radicular com o rebrote após o pastejo. A intensa renovação do sistema radicular pode reduzir o efeito do pisoteio animal sobre a estrutura do solo em pastagens (Trujillo et al., 2006).

No estudo de Petean et al. (2009), três anos após a implantação do SILP, a Ds na profundidade de $0,0-7,5 \mathrm{~cm}$ nos tratamentos $7\left(1,32 \mathrm{~kg} \mathrm{dm}^{-3}\right), 14(1,30$ $\left.\mathrm{kg} \mathrm{dm}^{-3}\right)$ e $21 \mathrm{~cm}\left(1,27 \mathrm{~kg} \mathrm{dm}^{-3}\right)$ apresentou valores estatisticamente iguais aos da profundidade de 7,5-
$15,0 \mathrm{~cm}\left(1,30,1,33\right.$ e $1,30 \mathrm{~kg} \mathrm{dm}^{-3}$ para 7,14 e $21 \mathrm{~cm}$, respectivamente). Já sete anos após o início do experimento, verificaram-se reduções nas Ds dos tratamentos $7,14 \mathrm{e} 21 \mathrm{~cm}$ da profundidade de $0,0-7,5 \mathrm{~cm}$, o que indica a ocorrência de processos de resiliência estrutural, promovendo a recuperação física do solo com o tempo. Isto pode também ser visualizado na camada de 7,5-15,0 cm, em que, após sete anos, os tratamentos 7 e $21 \mathrm{~cm}$ apresentaram $\mathrm{Ds}$ da profundidade de $0,0-7,5 \mathrm{~cm}$ estatisticamente inferiores a 7,5-15,0 cm. As Ds dos tratamentos $28 \mathrm{~cm}$ e testemunha que eram, respectivamente, 1,26 e $1,22 \mathrm{~kg} \mathrm{dm}^{-3}$ na profundidade de $0,0-7,5 \mathrm{~cm}$ e 1,32 e $1,29 \mathrm{~kg} \mathrm{dm}^{-3}$ na profundidade de 7,5-15,0 cm no estudo de Petean et al. (2009), não sofreram alterações substanciais. Esses resultados sugeriram que a maior supressão do azevém pela aveia, e o ciclo mais curto da aveia em relação ao azevém, provavelmente reduz o volume de raízes no solo, bem como a atividade das raízes em termos de uso de água do solo, diminuindo os efeitos dos ciclos de umedecimento e secagem, assim como a regeneração do solo. Entre os fatores que influenciam a regeneração do solo estão: os ciclos de umedecimento e secagem, as atividades biológicas decorrentes do crescimento de raízes e a atividade da fauna edáfica (Seybold et al., 1999; Gregory et al., 2009).

Para a PT, o tratamento de $21 \mathrm{~cm}$ foi superior ao de $7 \mathrm{~cm}$ na profundidade de $0,0-7,5 \mathrm{~cm}$; e o de $14 \mathrm{~cm}$ foi superior ao $7 \mathrm{~cm}$, na profundidade de $7,5-15,0 \mathrm{~cm}$.
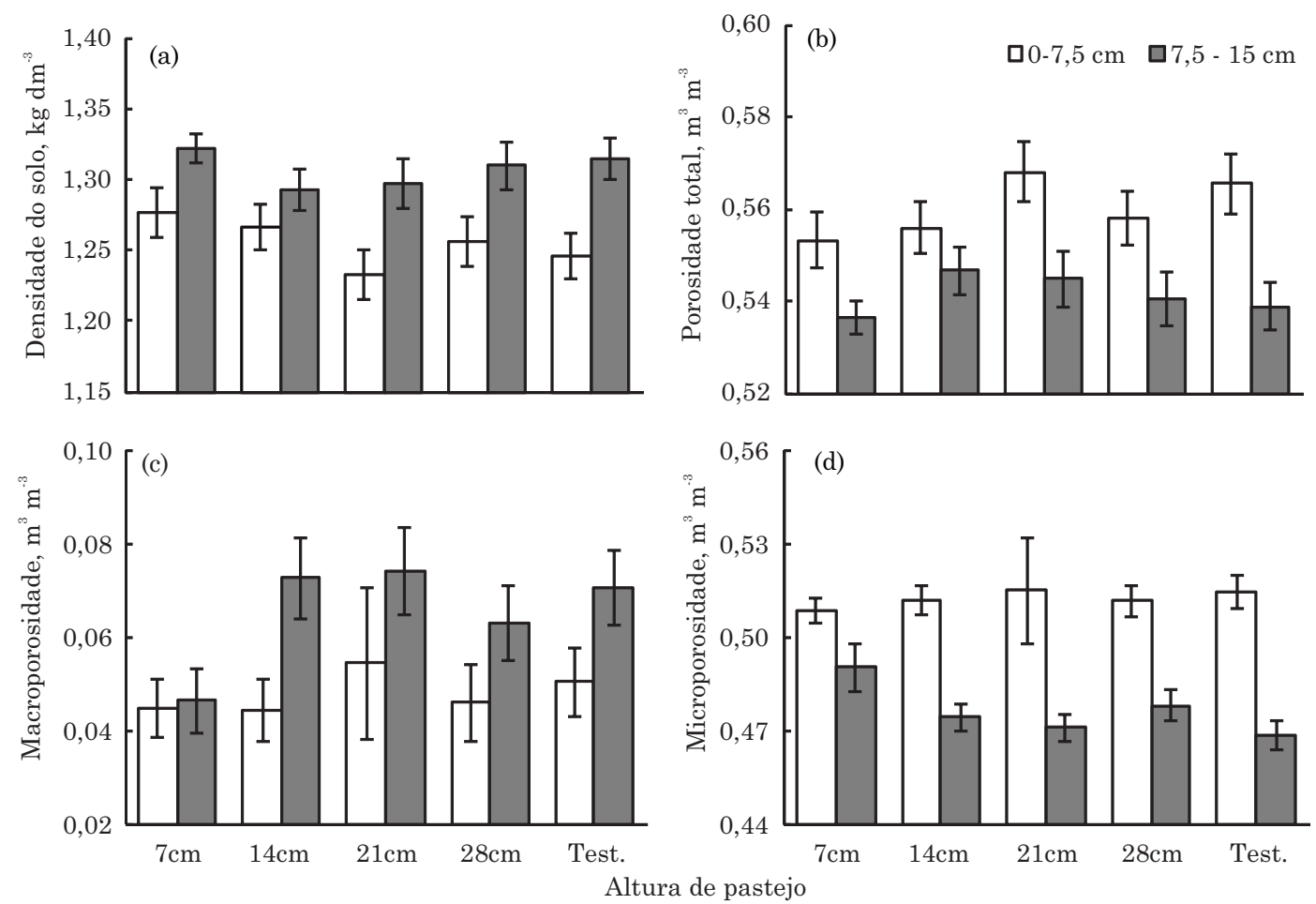

Figura 1. Densidade do solo (a), porosidade total (b), macroporosidade (c) e microporosidade (d) para os tratamentos de 7, 14, 21, $28 \mathrm{~cm}$ e testemunha (Test), nas profundiades de 0,0-7,5 e 7,5-15,0 cm. A sobreposição do intervalo de confiança da média índica ausência de diferença estatística entre os valores $(p<0,05)$. 
Ao analisar macro e microporosidade, observou-se que houve igualdade estatística na profundidade de 0,0$7,5 \mathrm{~cm}$, enquanto ocorreram diferenças na profundidade de 7,5-15,0 cm, em que o tratamento $7 \mathrm{~cm}$ apresentou menor macroporosidade e maior microporosidade que os outros tratamentos. A menor PT do tratamento de $7 \mathrm{~cm}$ em relação ao de $14 \mathrm{~cm}$ na profundidade de 7,5-15,0 cm decorreu da redução da macroporosidade, que apresentou valores aproximadamente $50 \%$ menores. A Ds, PT, macro e microporosidade evidenciaram que apesar de alguns tratamentos apresentarem diferenças, no geral, os resultados não permitiram conclusão sobre qual tratamento proporcionou melhor qualidade física do solo, mas indicaram que o tratamento de $7 \mathrm{~cm}$ foi o mais restritivo para esses atributos na profundidade de 7,5-15,0 cm.

A POMAC não apresentou diferenças entre tratamentos e profundidades (Figura 2). Os valores ótimos para POMAC ainda não estão bem esclarecidos (Reynolds et al., 2008); no entanto, essa variável foi importante por fornecer indicativos da infiltração da água e capacidade de aeração, logo após o solo ser saturado. Os resultados de POMAC são diferentes dos obtidos por Petean et al. (2009), em que 7, 14 e $21 \mathrm{~cm}$ haviam apresentado menor POMAC que $28 \mathrm{~cm} \mathrm{e}$ testemunha. Isso sugeriu que os tratamentos, em que o desenvolvimento do azevém apresentou menor supressão pela aveia $(7,14$ e $21 \mathrm{~cm})$, em razão do menor sombreamento, resultaram provavelmente em maior renovação radicular, permitindo maior regeneração de macroporos com diâmetro $>300 \mathrm{~mm}$ (drenados a $1 \mathrm{kPa}$ ). Ja a POMAT apresentou maiores valores nos tratamentos de $28 \mathrm{~cm}$ e testemunha, em relação ao tratamento de $7 \mathrm{~cm}$. A redução nesse tratamento deve-se à pressão aplicada e à intensidade do pisoteio, ou seja, como há maior deslocamento dos animais na área quando há menor oferta de forragem, há maior pisoteio. Particularmente no tratamento de $7 \mathrm{~cm}$, a reduzida quantidade de resíduos pode ter contribuído, uma vez que a palha que cobre o solo atenua a pressão aplicada instantaneamente sobre o solo na proporção direta de sua quantidade, dissipando parte da energia de compactação, conforme estabelecem Braida et al. (2006). Assim, era esperado que o tratamento de $7 \mathrm{~cm}$, que apresentou menor cobertura e maior intensidade de pisoteio, fosse o mais restritivo; isso evidenciou que o controle da altura de pastejo é elemento-chave para o manejo das áreas sob SILP.

A CATSOLO e a CAMAT apresentaram comportamento similar da POMAC para a profundidade de $0,0-7,5 \mathrm{~cm}$. A CATSOLO e a CAMAT podem indicar as condições de solo para o fluxo de gases na interface solo-raiz. Conforme Grable \& Siemer (1968), o valor de porosidade de aeração de $0,10 \mathrm{~m}^{3} \mathrm{~m}^{-3}$
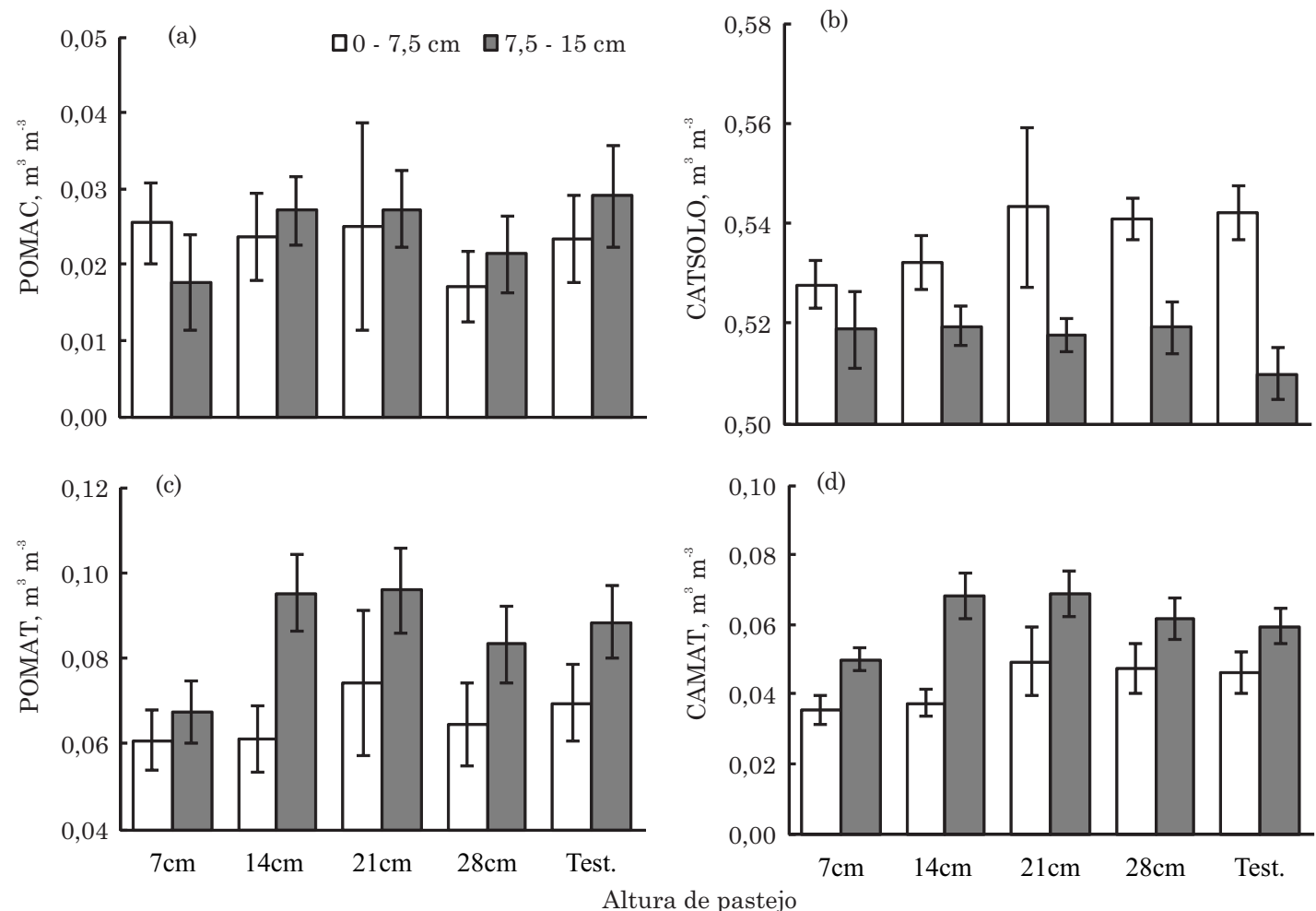

Figura 2. Porosidade no domínio dos macroporos - POMAC (a), porosidade no domínio da matriz do solo POMAT (b), capacidade de ar no solo - CATSOLO (c) e capacidade de ar na matriz do solo - CAMAT (d), para os tratamentos de 7,14, 21, $28 \mathrm{~cm}$ e testemunha (Test), nas profundiades de 0,0-7,5 e 7,5-15,0 cm. A sobreposição do intervalo de confiança da média índica ausência de diferença estatística entre os valores $(p<0,05)$. 
(10 \%) pode ser considerado o mínimo para uma adequada difusão de gases na maioria dos solos. Contudo, na profundidade de $0,0-7,5 \mathrm{~cm}$, a CATSOLO evidenciou valores inferiores aos considerados ideais $\left(<0,08 \mathrm{~m}^{3} \mathrm{~m}^{-3}\right)$ e não pode ser afirmado que foram decorrentes das alterações deletérias causadas pelo pisoteio animal, pois a testemunha também apresentou tal resultado. No SILP, os efeitos do tráfego durante a cultura da soja no verão podem provocar alterações estruturais no solo e essas serem observadas nos dados coletados pós-pastejo, podendo essa ser a justificativa para os valores de CATSOLO, pois não há como separar os efeitos do pisoteio e do tráfego de máquinas, ressaltando que o pisoteio pode atingir maior porcentagem da área. Junto aos possíveis efeitos do manejo, também há a possibilidade que os valores de CATSOLO inferiores a $10 \%$ sejam uma característica desse solo, que demonstrou elevado teor de argila e valores de densidade.

Por meio da CATSOLO, CAMAT, POMAC, macro e microporosidade, não se pode afirmar que a menor altura de pastejo resulte em menor qualidade física do solo, na profundidade de $0,0-7,5 \mathrm{~cm}$; porém, Ds $(21 \mathrm{~cm}<7 \mathrm{~cm})$, PT $(21 \mathrm{~cm}>7 \mathrm{~cm})$ e POMAT (testemunha $=28 \mathrm{~cm}>7 \mathrm{~cm}$ ) evidenciaram que $7 \mathrm{~cm}$ foi mais restritivo não apenas para profundidade de 7,5-15,0 cm, mas também na de 0,0-7,5 cm. Na profundidade de 7,5-15,0 cm, a CATSOLO apresentou tratamento de $7 \mathrm{~cm}$ inferior ao de $14,21 \mathrm{~cm} \mathrm{e}$ testemunha, enquanto a CAMAT demonstrou que o tratamento de $7 \mathrm{~cm}$ foi inferior aos demais. Isso sugeriu que os efeitos deletérios da manutenção da altura de pastejo de $7 \mathrm{~cm}$ atingiram também essa profundidade, concordando os resultados da macroporosidade, que apresentou menores valores no tratamento de $7 \mathrm{~cm}$, e corroboram os resultados de Lanzanova et al. (2007), em que a frequência de pastejo de aveia e azevém comprometeu a macroporosidade do solo na camada de 10,0-15,0 cm. Esses resultados discordaram dos de Bertol et al. (2000), os quais indicaram que os efeitos do manejo do solo associado ao pisoteio animal concentraram-se na camada superficial do solo $(0,0-5,0 \mathrm{~cm})$.

A capacidade de armazenamento de ar na profundidade de 0,0-7,5 cm não apresentou diferença estatística significativa entre os tratamentos, enquanto na profundidade de 7,5-15,0 cm o tratamento de $7 \mathrm{~cm}$ evidenciou valor inferior à testemunha, $14 \mathrm{e}$ $21 \mathrm{~cm}$ (Figura 3). Os indicadores de capacidade de armazenamento de água e ar do solo revelaram que o tratamento de $21 \mathrm{~cm}$ na profundidade de $0,0-7,5 \mathrm{~cm}$ e os tratamentos de 14 e $21 \mathrm{~cm}$ na profundidade de $7,5-15,0 \mathrm{~cm}$ foram os que demonstraram valores mais próximos do balanço ideal, em que 0,66 para a capacidade de armazenamento de água e 0,34 para a capacidade de armazenamento de ar, conforme Reynolds et al. (2002). Em razão das características e do manejo desse solo, os valores estão distantes dos considerados ideais; porém, corroboraram com os encontrados por Reynolds et al. (2002), próximos a
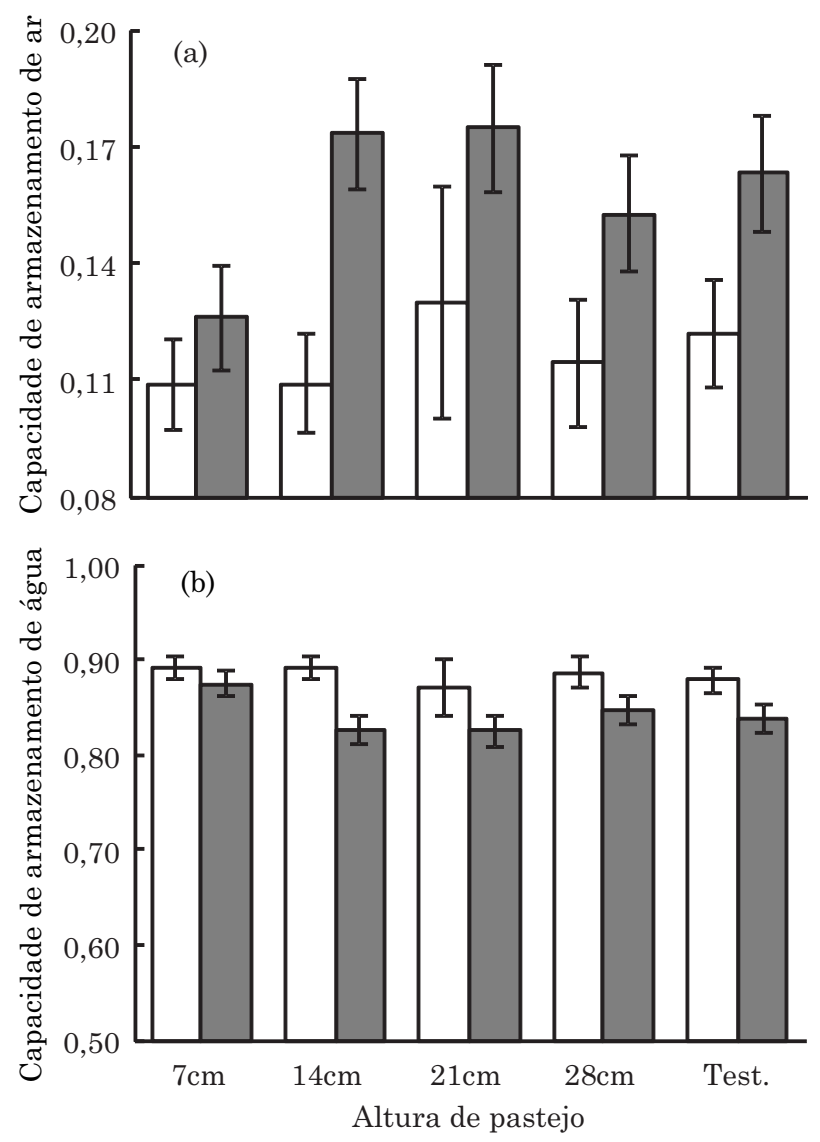

Figura 3. Capacidade de armazenamento de ar (a) e capacidade de armazenamento de água (b) para os tratamentos de 7, 14, 21, $28 \mathrm{~cm}$ e testemunha (Test), nas profundiades de 0,0-7,5 e 7,5-15,0 cm. A sobreposição do intervalo de confiança da média indica ausência de diferença estatística entre os valores $(p<0,05)$.

0,8 para capacidade de armazenamento de água, em sistema plantio direto.

No quadro 1, são apresentadas as equações ajustadas para a CRA e CRS. A Ds e os tratamentos não influenciaram a CRA, justificando o ajuste de uma equação para cada profundidade, que foi significativa. Conforme Hillel (1970), a retenção de água em altos valores de $\theta$ dependem da Ds e porosidade, enquanto para baixo valores de $\theta$ a textura e a superfície específica apresentaram grande influência. Assim, em razão de a Ds e porosidade terem apresentado resultados semelhantes, exceto no tratamento de $7 \mathrm{~cm}$, a ausência de diferença na CRA fez sentido. Para a CRS, não foi possível ajustar uma equação única, mas houve um coeficiente ajustado que não diferiu em cada profundidade (coeficiente $e$ para 0,0-7,5 cm e coeficiente $d$ para 7,5-15,0 cm). Assim, na profundidade de $0,0-7,5 \mathrm{~cm}$, a Ds influenciou positivamente a RP, porém a influência observada foi idêntica em todos os tratamentos. Entretanto, o $\theta$ motivou negativamente a RP. As diferenças estatísticas encontradas na CRS, ajustando curvas 
Quadro 1. Equações ajustadas para a curva de retenção de água do solo (CRA) e curva de resistência do solo à penetração (CRS), nas profundidades avaliadas

\begin{tabular}{|c|c|c|}
\hline \multirow{2}{*}{ Tratamento } & \multicolumn{2}{|c|}{ Profundidade } \\
\hline & $0,0-7,5 \mathrm{~cm}$ & $7,5-15,0 \mathrm{~cm}$ \\
\hline & & \\
\hline \multirow[t]{3}{*}{ Todos } & $\theta=0,5411 \Psi^{-0,0598}$ & $\theta=0,5333 \Psi^{-0,0696}$ \\
\hline & $F=11853,00 ; p<0,0001$ & $F=11118,70 ; p<0,0001$ \\
\hline & & \\
\hline \multirow[t]{2}{*}{7} & $\mathrm{RP}=0,2221 \mathrm{Ds}^{6,3036} \theta^{-1,3262}$ & $\mathrm{RP}=0,1814 \mathrm{Ds}^{6,2754} \theta^{-1,3789}$ \\
\hline & $\mathrm{F}=32,51 ; \mathrm{p}<0,0001$ & $\mathrm{~F}=6,99 ; \mathrm{p}=0,0123$ \\
\hline \multirow[t]{2}{*}{14} & $\mathrm{RP}=0,0494 \mathrm{Ds}^{6,3036} \theta^{-3,1502}$ & $\mathrm{RP}=0,1814 \mathrm{Ds}^{2,6029} \theta^{-2,4781}$ \\
\hline & $\mathrm{F}=76,19 ; \mathrm{p}<0,0001$ & $\mathrm{~F}=100,25 ; \mathrm{p}<0,0001$ \\
\hline \multirow[t]{2}{*}{21} & $\mathrm{RP}=0,1096 \mathrm{Ds}^{6,3036} \theta^{-2,2608}$ & $\mathrm{RP}=0,1814 \mathrm{Ds}^{4,3881} \theta^{-1,9667}$ \\
\hline & $\mathrm{F}=85,46 ; \mathrm{p}<0,0001$ & $\mathrm{~F}=31,31, \mathrm{p}<0,0001$ \\
\hline \multirow[t]{2}{*}{28} & $\mathrm{RP}=0,0733 \mathrm{Ds}^{6,3036} \theta^{-2,6325}$ & $\mathrm{RP}=0,1814 \mathrm{Ds}^{5,3282} \theta^{-1,6941}$ \\
\hline & $\mathrm{F}=80,17 ; \mathrm{p}<0,0001$ & $\mathrm{~F}=25,02 ; \mathrm{p}<0,0001$ \\
\hline \multirow[t]{2}{*}{ Testemunha } & $\mathrm{RP}=0,0836 \mathrm{Ds}^{6,3036} \theta^{-2,4121}$ & $\mathrm{RP}=0,1814 \mathrm{Ds}^{4,7694} \theta^{-1,8069}$ \\
\hline & $\mathrm{F}=105,98 ; \mathrm{p}<0,0001$ & $\mathrm{~F}=57,29 ; \mathrm{p}<0,0001$ \\
\hline
\end{tabular}

Teor volumétrico de água $\left(\theta=\mathrm{m}^{3} \mathrm{~m}^{-3}\right)$; potencial mátrico de água do solo $(\Psi=\mathrm{kPa})$; resistência do solo à penetração $(\mathrm{RP}=\mathrm{MPa})$; e densidade do solo $\left(\mathrm{Ds}=\mathrm{kg} \mathrm{dm}^{-3}\right.$ ).

diferentes para cada tratamento, indicaram que essa apresentou maior sensibilidade em distinguir os efeitos do manejo do que a CRA. Moreira et al. (2012) também observaram que a RP evidenciou maior sensibilidade para descrever as diferenças, quando comparadas com Ds, porosidade de aeração e permeabilidade do solo ao ar.

As estimativas de $\theta_{\mathrm{CC}}, \theta_{\mathrm{PMP}}$ e $\theta_{\mathrm{RP}}$ e $\theta_{\mathrm{PA}}$ para os valores limites de $-10 \mathrm{kPa},-1500 \mathrm{kPa}, 3,5 \mathrm{MPa}$ e $0,10 \mathrm{~m}^{3} \mathrm{~m}^{-3}$, respectivamente, são apresentadas na figura 4. Constatou-se que o aumento da Ds foi acompanhado do aumento do $\theta_{\mathrm{RP}}$, bem como do decréscimo de $\theta_{\mathrm{PA}}$, corroborando os resultados de Silva et al. (1994), Tormena et al. (2007) e Betioli Junior et al. (2012). Nas duas camadas, tanto $\theta_{\mathrm{CC}}$ como $\theta_{\mathrm{PA}}$ determinaram o limite superior do $\mathrm{IHO}$; com o aumento da Ds, a $\theta_{\mathrm{PA}}$ substituiu a $\theta_{\mathrm{CC}}$ como limite superior do IHO. Os valores de Ds, em que $\theta_{\mathrm{PA}}$ substituiu a $\theta_{\mathrm{CC}}$, foram de 1,23 e $1,27 \mathrm{~kg} \mathrm{dm}^{-3}$ para as profundidades de 0,0-7,5 e 7,5-15,0 cm, respectivamente, corroborando os resultados de Petean et al. (2010). Assim, os tratamentos de 7, 14, $21,28 \mathrm{~cm}$ e testemunha apresentaram, respectivamente, 77,$78 ; 83,33 ; 50,00 ; 75,00$ e $58,33 \%$ das amostras em $0,0-7,5 \mathrm{~cm}$; e 97,$22 ; 80,56 ; 77,78 ; 75,00$ e $86,11 \%$ das amostras em 7,5-15,0 cm com Ds superior ao valor que $\theta_{\mathrm{PA}}$ substituiu a $\theta_{\mathrm{CC}}$. Esses resultados reforçaram os resultados de CATSOLO, que apresentou valores inferiores aos considerados ideais, e demonstraram que a aeração foi limitante também ao IHO nas duas profundidades.

A degradação física do solo do tratamento de $7 \mathrm{~cm}$, observada pelos indicadores de Reynolds, Ds, PT, macro e microporosidade, não foi evidenciada pelo IHO, exceto que a inclinação do $\theta_{\mathrm{RP}}$ foi maior nesse tratamento, indicando que a transição de $\mathrm{Ds}$, em que $\mathrm{o} \mathrm{IHO}=\mathrm{AD}$ para $\mathrm{IHO}=0$, ocorreu numa faixa menor de Ds nesse tratamento, para as duas profundidades. Isso ocorreu, pois, de um lado, há intenso pisoteio e pequena atenuação do seu efeito em razão da menor cobertura e, por outro lado, áreas onde não há pisoteio em que pode ter $\mathrm{IHO}=\mathrm{AD}$, ocorrendo concentração de dados nas extremidades, o que influenciou o modelo da CRS. Nos outros tratamentos, em que há maior cobertura e menor intensidade do pisoteio, podiam ocorrer diversas situações como ocorrência de pisoteio com cobertura para atenuar a frequência de pisoteio e cobertura insuficiente, entre outras, em que a concentração de dados nas extremidades foi diluída, e o $\theta_{\mathrm{RP}}$ apresentou menor inclinação.

O limite inferior do IHO foi definido quase integralmente pelo $\theta_{\mathrm{RP}}$. Esses resultados corroboraram os de Tormena et al. (2007), Kaiser et al. (2009), Fidalski et al. (2010) e Calonego \& Rosolem (2011), em que o $\theta_{\mathrm{RP}}$ mais frequentemente reduziu o IHO em solos sob diferentes condições de textura e manejo. $\mathrm{O}$ $\theta_{\mathrm{PMP}}=\theta_{\mathrm{RP}}$ ocorreu na Ds de 1,$24 ; 1,16 ; 1,19 ; 1,19$; e $1,21 \mathrm{~kg} \mathrm{dm}^{-3}$ nos tratamentos de $7,14,21,28 \mathrm{~cm} \mathrm{e}$ testemunha na profundidade de $0,0-7,5 \mathrm{~cm}$, respectivamente, enquanto na profundidade $7,5-15,0 \mathrm{~cm}$ foi de 1,$25 ; 1,16 ; 1,18 ; 1,21 ;$ e $1,21 \mathrm{~kg} \mathrm{dm}^{-3}$ nos tratamentos de $7,14,21,28 \mathrm{~cm}$ e testemunha, respectivamente. $O$ maior valor foi observado em $7 \mathrm{~cm}$ nas duas profundidades. Esse maior valor indicou a possibilidade de maior amplitude da situação em que o IHO $=\mathrm{AD}$, fato confirmado pelos dados, onde os tratamentos de $7,14,21,28 \mathrm{~cm}$ e testemunha apresentaram, respectivamente, 27,78; 2,78; 25,00; 11,11 ; e $22,22 \%$ dos dados com IHO = AD, na camada 

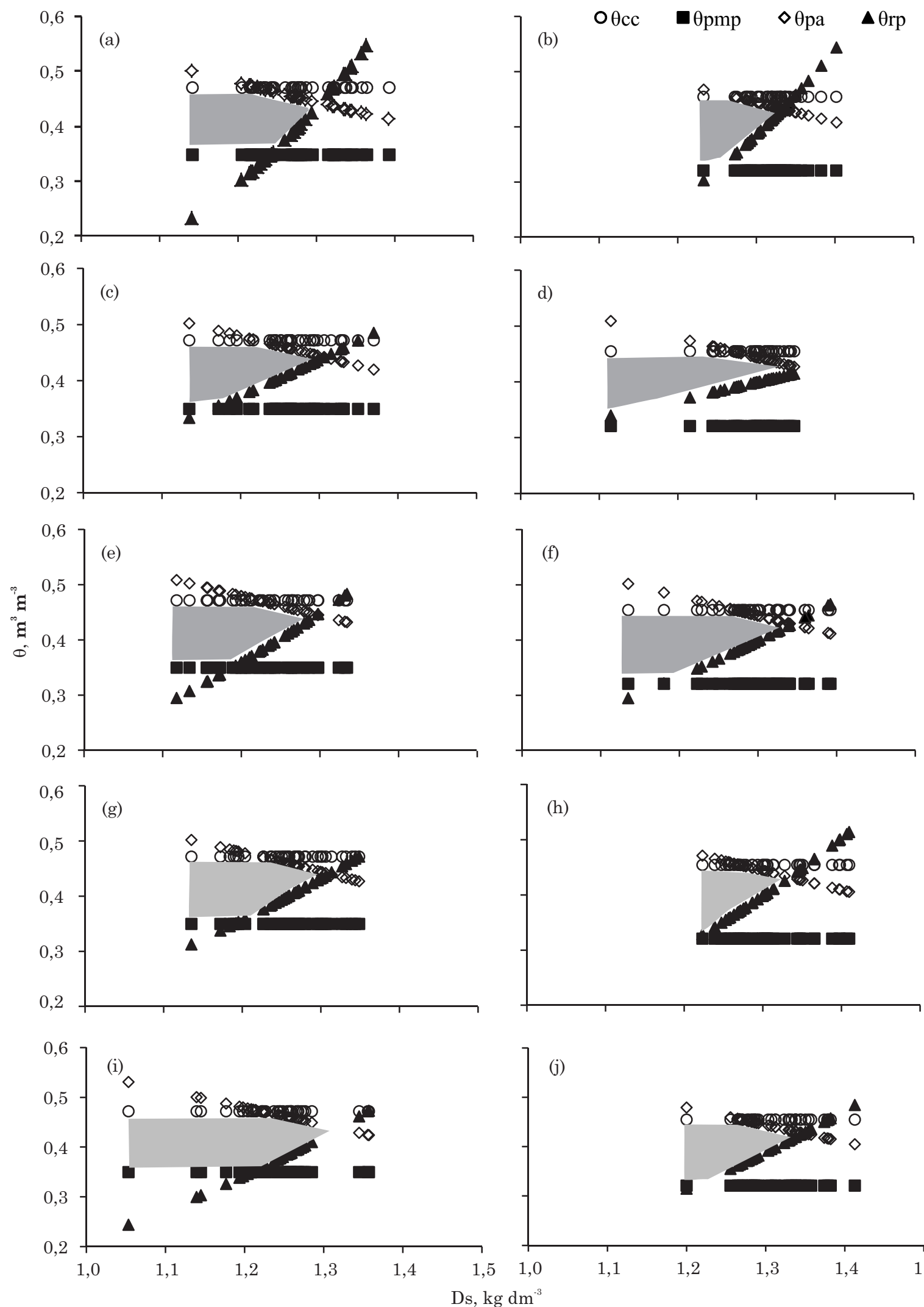

(j)

Figura 4. Variação do teor de água $(\theta)$ com a densidade do solo (Ds) nos níveis críticos da capacidade de campo $\left(\theta_{\mathrm{CC}}\right)$, ponto de murcha permanente $\left(\theta_{\mathrm{PMP}}\right)$, resistência à penetração $\left(\theta_{\mathrm{RP}}\right)$ e porosidade de aeração $\left(\theta_{\mathrm{PA}}\right)$ nos tratamentos de $7 \mathrm{~cm}(\mathrm{a}, \mathrm{b}), 14 \mathrm{~cm}(\mathrm{c}, \mathrm{d}), 21 \mathrm{~cm}(\mathrm{e}, \mathrm{f}), 28 \mathrm{~cm}(\mathrm{~g}, \mathrm{~h})$ e testemunha $(\mathrm{i}, \mathrm{j})$, nas profundidades de 0,0-7,5 (a, c, e, g, i) e 7,5-15,0 cm (b, d, f, h, j). As áreas em cinza correspondem ao IHO. 
de 0,0-7,5 $\mathrm{cm}$. Porém, isso não indicou que o tratamento de $7 \mathrm{~cm}$ foi o melhor. Conforme figura 5 , o tratamento com $7 \mathrm{~cm}$ apresentou a maior quantidade de amostras com Ds > Dsc nas duas profundidades, evidenciando no mínimo o dobro de dados nessa condição em relação aos outros tratamentos da profundidade de $0,0-7,5 \mathrm{~cm}$. Para a camada de $7,5-15,0 \mathrm{~cm}, 7,14,21 \mathrm{~cm}$ e testemunha apresentaram $2,78 \%$, e $28 \mathrm{~cm}, 0 \%$ das amostras com IHO = AD.

Um menor valor de Dsc aumentou a possibilidade de que os valores de $\mathrm{Ds}$ atingissem valores maiores que o crítico, condição encontrada em solos que apresentaram estrutura degradada. Contudo, os valores de Dsc não apresentaram grande variação entre os tratamentos pastejados, sendo semelhantes também com a testemunha. Entre os tratamentos com pastejo, o tratamento com $21 \mathrm{~cm}$ apresentou as menores proporções de Ds $>$ Dsc (Figura 5) em 0,0-7,5 cm, porém ainda com boa diferença em relação à testemunha e aos valores próximos a 14 e $28 \mathrm{~cm}$.
Esses resultados sugeriram também que os tratamentos em que o desenvolvimento do azevém teve maior supressão pela aveia ( $28 \mathrm{~cm}$ e testemunha), em razão do maior sombreamento e competição, apresentaram menor regeneração do solo, ou seja, houve equilíbrio entre regeneração e degradação da qualidade física do solo, em que o tratamento de 21 $\mathrm{cm}$ apresentou melhor relação regeneração/ degradação do que $28 \mathrm{~cm}$ na profundidade de 0,0 $7,5 \mathrm{~cm}$. Esse resultado foi reforçado pelos outros índices como Ds e PT. Além disso, apesar da igualdade estatística com outros tratamentos, a POMAC, POMAT, CATSOIL, CAMAT, macro e microporosidade também apresentaram valores no tratamento de $21 \mathrm{~cm}$ com as melhores condições. Para 7,5-15,0 cm, o tratamento de $14 \mathrm{~cm}$ não apresentou amostras com Ds > Dsc, seguido por $21 \mathrm{~cm} \mathrm{e}$ testemunha, sugerindo que, diferentemente da macroporosidade, CATSOLO e CAMAT, não houve comportamento sistemático ligado à compactação do solo pelo pisoteio animal.
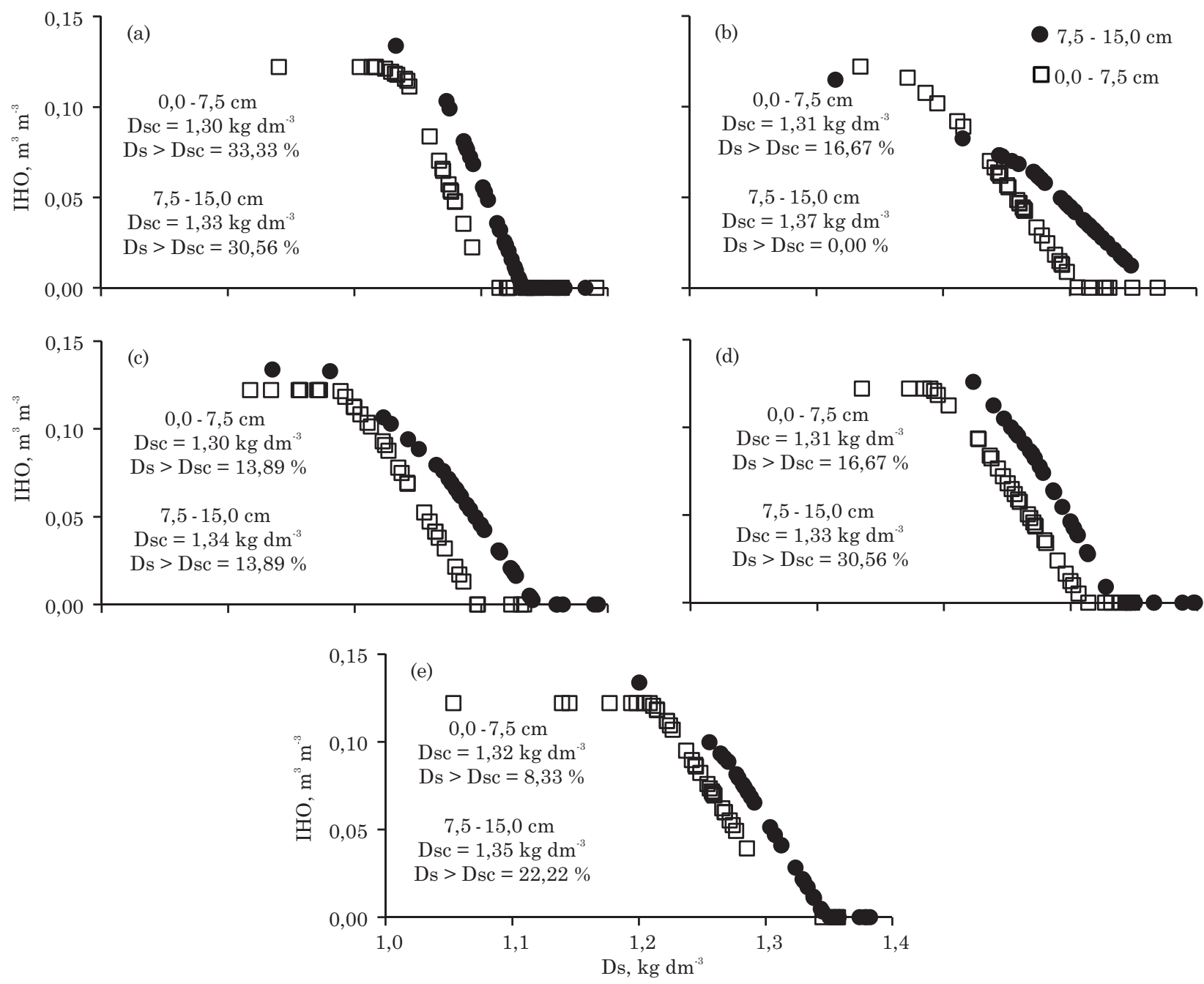

Figura 5. Variação do intervalo hídrico ótimo (IHO) com a densidade do solo (Ds) nos tratamentos $7 \mathrm{~cm}$ (a), $14 \mathrm{~cm}(\mathrm{~b}), 21 \mathrm{~cm}(\mathrm{c}), 28 \mathrm{~cm}$ (d) e testemunha (e), nas profundidades de 0,0-7,5 e 7,5-15,0 cm. 
Assim, de modo geral, houve indicativos de que os efeitos do manejo em SILP ocorreram nas camadas de 0,0-7,5 e 7,5-15,0 cm; porém, a avaliação dos atributos físicos não indicou que esses responderam linearmente à intensificação do pastejo nas duas camadas. Na camada de 7,5-15,0 cm, a maior Ds encontrada poderia indicar uma situação mais restritiva; no entanto, essa camada, com exceção do tratamento de $7 \mathrm{~cm}$, apresentou maior macroporosidade, CAMAT e CATSOLO, que resultou em maior capacidade de armazenamento de ar e IHO, evidenciando maior Dsc (Figura 5). Na camada de 0,0-7,5 cm, houve menor Ds e maior PT, microporosidade e POMAT. Isso demonstrou que a integração de diversos atributos físicos para avaliação da qualidade física do solo foi positiva e desejável para melhor entendimento do sistema, e que as avaliações com poucos atributos puderam levar a equívocos de que os efeitos do manejo ocorressem em uma determinada camada, quando também pudessem ocorrer em outras camadas.

\section{CONCLUSÕES}

1. A hipótese deste trabalho foi confirmada, pois a intensificação do pastejo alterou a Ds, macroporosidade, POMAT, CATSOLO, CAMAT e capacidade de armazenamento de água e ar.

2. A altura de pastejo de $7 \mathrm{~cm}$ resultou em redução da qualidade física do solo indicada pela Ds, PT, POMAT e quantidade de amostras com Ds > Dsc, na profundidade de 0,0-7,5 cm, e, pela macroporosidade, CAMAT, CATSOLO e capacidade de armazenamento de ar, na profundidade de 7,5-15,0 cm, após sete anos de sistema integração lavoura-pecuária.

\section{LITERATURA CITADA}

BALL, B.C. \& HUNTER, R. The determination of water release characteristics of soil cores al low suctions. Geoderma, 43:95-212, 1988 .

BERTOL, I.; ALMEIDA, J.A.; ALMEIDA, E.X. \& KURTZ, C. Propriedades físicas do solo relacionado a diferentes níveis de oferta de forragem de capim elefante-anão cv Motti. Pesq. Agropec. Bras., 35:1047-1054, 2000.

BETIOLI JUNIOR, E.; MOREIRA, W.H.; TORMENA, C.A.; FERREIRA, C.J.B.; SILVA, A.P. \& GIAROLA, N.F.B. Intervalo hídrico ótimo e grau de compactação de um Latossolo Vermelho após 30 anos sob plantio direto. R. Bras. Ci. Solo, 36:971-982, 2012.

BONO, J.A.M.; MACEDO, M.C.M. \& TORMENA, C.A. Qualidade física do solo em um latossolo vermelho da região sudoeste dos cerrados sob diferentes sistemas de uso e manejo. R. Bras. Ci. Solo, 37:743-753, 2013.
BRAIDA, J.A.; REICHERT, J.A.; VEIGA, M. \& REINERT, D.J. Resíduos vegetais na superfície e carbono orgânico do solo e suas relações com a densidade máxima obtida no ensaio Proctor. R. Bras. Ci. Solo, 30:605-614, 2006.

BUSSCHER, W.J. Adjustment of flat-tipped penetrometer resistance data to common water content. Trans. Am. Soc. Agric. Eng., 3:519-524, 1990.

CALONEGO, J.C.; ROSOLEM, C.A. Least limiting water range in soil under crop rotations and chiseling. R. Bras. Ci. Solo, 35:759-771, 2011.

CARNEIRO, M.A.C.; SOUZA, E.D.; REIS, E.F.; PEREIRA, H.S. \& AZEVEDO, W.R. Atributos físicos, químicos e biológicos de solo de cerrado sob diferentes sistemas de uso e manejo. R. Bras. Ci. Solo, 33:147-157, 2009.

CONTE, O.; FLORES, J.P.C.; CASSOL, L.C.; ANGHINONI, I.; CARVALHO, P.C.F.; LEVIEN, R. \& WESP, C.L. Evolução de atributos físicos de solo em sistema de integração lavoura-pecuária. Pesq. Agropec. Bras., 46:1301-1309, 2011.

DIAS JUNIOR, M.S. \& MIRANDA, E.E.V. Comportamento da curva de compactação de cinco solos da região de Lavras (MG). Ci. Agrotec., 24:337-346, 2000.

EHLERS, W.; KÖPKE, U.; HESSE, F. \& BÖHM, W. Penetration resistance and root growth of oats in tilled and untilled loess soil. Soil Till. Res., 3:261-275, 1983.

EMPRESA BRASILEIRA DE PESQUISA AGROPECUÁRIA . EMBRAPA. Centro Nacional de Pesquisa de Solos. Sistema brasileiro de classificação de solos. Brasília, Embrapa Produção de Informação, 2006. 306p.

EMPRESA BRASILEIRA DE PESQUISA AGROPECUÁRIA . EMBRAPA. Manual de métodos de análise de solo. 2.ed. Rio de Janeiro, Centro Nacional de Pesquisa de Solos, 1997. 212p. (Documentos, 1)

FIDALSKI, J.; TORMENA, C.A. \& ALVES, S.J. Intervalo hídrico ótimo de um Latossolo Vermelho distrófico, após o primeiro período de pastejo contínuo de Brachiaria ruziziensis, em sistema integração lavoura-pecuária. R. Bras. Ci. Solo, 37:775-783, 2013.

FIDALSKI, J.; TORMENA, C.A. \& SILVA, A.P. Least limiting water range and physical quality of soil under groundcover management systems in citrus. Sci. Agric., 67:448-453, 2010.

FLORES, J.P.C.; ANGHINONI, I.; CASSOL, L.C.; CARVALHO, P.C.F.; LEITE, J.G.D.B. \& FRAGA, T.I. Atributos físicos do solo e rendimento de soja em sistema plantio direto em integração lavoura-pecuária com diferentes pressões de pastejo. R. Bras. Ci. Solo, 31:771-780, 2007.

GiAROLA, N.F.B.; TORMENA, C.A. \& DUTRA, A.C. Degradação física de um Latossolo Vermelho utilizado para produção intensiva de forragem. R. Bras. Ci. Solo, 31:863 873, 2007.

GRABLE, A.R. \& SIEMER, E.G. Effects of bulk density, aggregate size, and soil water suction on oxygen diffusion, redox potential and elongation of corn roots. Soil Sci. Soc. Am. J., 32:180-186, 1968. 
GREGORY, A.S.; WATTS, C.W.; GRIFFITHS, B.S.; HALLET, P.D.; KUAN, H.L. \& WHITMORE, A.P. The effect of long-term soil management on the physical and biological resilience of a range of arable and grassland soils in England. Geoderma, 153:172-185, 2009.

GROSSMAN, R.B. \& REINSCH, T.G. Bulk density and linear extensibility. In: DANE, J.H. \& TOPP, G.C., eds. Methods of soil analysis. 3.ed. Madison, American Society of Agronomy, Soil Science Society of America, 2002. Part 4. p.201-228.

HILLEL, D. Solo e água, fenômenos e princípios físicos. Porto Alegre, Universidade Federal do Rio Grande do Sul, 1970. $231 \mathrm{p}$.

KAISER, D.G.; REINERT, D.J.; REICHERT, J.M.; COLLARES, G.L. \& KUNZ, M. Intervalo hídrico ótimo no perfil explorado pelas raízes de feijoeiro em um Latossolo. $\mathrm{R}$. Bras. Ci. Solo, 33:845-855, 2009.

KLUTE, A. Water retention: Laboratory methods. In: KLUTE, A., ed. Methods of soil analysis: Physical and mineralogical methods. 2.ed. Madison, America Society of Agronomy, 1986. p.635-660.

LANZANOVA, M.E.; NICOLOSO, R.S.; LOVATO, T.; ELTZ, F.L.F.; AMADO, T.J.C. \& REINERT, D.J. Atributos físicos do solo em sistema de integração lavoura-pecuária sob plantio direto. R. Bras. Ci. Solo, 31:1131 1140, 2007.

LEÃO, T.P.; SILVA, A.P.; PERFECT, E. \& TORMENA, C.A. An algorithm for calculating the least limiting water range of soil using SAS. Agron. J., 97:1210-1215, 2005.

MUELLER, L.; KAY, B.D.; BEEN, B.; HU, C.; ZHANG, Y.; WOLFF, M.; EULENSTEIN, F. \& SCHINDLER, U. Visual assessment of soil structure: Part II. Implications of tillage, rotation and traffic on sites in Canada, China and Germany. Soil Till. Res., 103:188-196, 2008.

MARCHÃO, R.L.; BALBINO, L.C.; SILVA, E.M.; SANTOS JUNIOR, J.D.G.; SÁ, M.A.C.; VILELA, L. \& BECQUER, T. Qualidade física de um Latossolo Vermelho sob sistemas de integração lavoura-pecuária no Cerrado. Pesq. Agropec. Bras., 42:873-882, 2007.

MORAES, M.T.; DEBIASI, H.; CARLESSO, R.; FRANCHINI, J.C. \& SILVA, V.R. Critical limits of soil penetration resistance in a Rhodic Eutrudox. R. Bras. Ci. Solo, 38:288298, 2014.

MOREIRA, W.H.; BETIOLI JUNIOR, E.; PETEAN, L.P.; TORMENA, C.A.; ALVES, S.J.; COSTA, M.A.T. \& FRANCO, H.H.S. Atributos físicos de um Latossolo Vermelho distroférrico em sistema de integração lavourapecuária. R. Bras. Ci. Solo, 36:389-400, 2012.

MOTT, G.O. \& LUCAS, H.L. The design, conduct, and interpretation of grazing trials on cultivated and improved pastures. In: INTERNATIONAL GRASSLAND CONGRESS, 6., 1952, State College. Proceedings... State College, 1952. p.1380-1385.

PAYTON, M.E.; MILLER, A.E. \& RAUN, W.R. Testing statistical hypotheses using standard error bars and confidence intervals. Commun. Soil Sci. Plant Anal., 31:547-551, 2000.
PETEAN, L.P.; TORMENA, C.A. \& ALVES, S.J. Intervalo hídrico ótimo de um Latossolo Vermelho distroférrico sob plantio direto em sistema de integração lavoura-pecuária. R. Bras. Ci. Solo, 34:1515-1526, 2010.

PETEAN, L.P.; TORMENA, C.A.; FIDALSKI, J. \& ALVES, S.J. Altura de pastejo de aveia e azevém e qualidade física de um Latossolo Vermelho distroférrico sob integração lavoura- pecuária. Semina: Ci. Agron., 30:1009-1016, 2009.

REGAZZI, A.J. Teste para verificar a igualdade de parâmetros e a identidade de modelos de regressão não-linear. $R$. Ceres, 50:9-26, 2003.

REICHARDT, K. Capacidade de campo. R. Bras. Ci. Solo, 12:211-16, 1988.

REYNOLDS, W.D.; BOWMAN, B.T.; DRURY, C.F.; TAN, C.S. \& LU, X. Indicators of good soil physical quality: Density and storage parameters. Geoderma, 110:131-146, 2002.

REYNOLDS, W.D.; DRURY, C.F.; TAN, C.S.; FOX, C.A. \& YANG, X.M. Use of indicators and pore volume-function characteristics to quantify soil physical quality. Geoderma, 152:252-263, 2009.

REYNOLDS, W.D.; DRURY, C.F.; YANG, X.M. \& TAN, C.S. Optimal soil physical quality inferred through structural regression and parameter interactions. Geoderma, 146:466-474, 2008.

SAS Institute. SAS: User's guide: statistics. 9.ed. Cary, 2002. 943p.

SAVAGE, M.J.; RITCHIE, J.T.; BLAND, W.L. \& DUGAS, W.A. Lower limit of soil water availability. Agron. J., 88:844851, 1996.

SEYBOLD, C.A.; HERRICK, J.E. \& BREJDA, J.J. Soil resilience: A fundamental component of soil quality. Soil Sci., 164:224-234, 1999.

SILVA, A.P. \& KAY, B.D. Effect of soil water content variation on the least limiting water range. Soil Sci. Soc. Am. J., 61:884-888, 1997.

SILVA, A.P.; KAY, B.D. \& PERFECT, E. Characterization of the least limiting water range. Soil Sci. Soc. Am. J., 58:1775-1781, 1994.

SPERA, S.T.; SANTOS, H.P.; FONTANELI, R.S. \& TOMM, G.O. Atributos físicos de um Hapludox em função de sistemas de produção integração lavoura-pecuária (ILP), sob plantio direto. Acta Sci. Agron., 32:37-44, 2010.

TORMENA, C.A.; ARAÚJO, M.A.; FIDALSKI, J. \& COSTA, J.M. Variação temporal do intervalo hídrico ótimo de um Latossolo Vermelho distroférrico em sistemas de plantio direto. R. Bras. Ci. Solo, 31:211-219, 2007.

TORMENA, C.A.; SILVA, A.P. \& LIBARDI, P.L. Soil physical quality of a Brazilian Oxisol under two tillage systems using the least limiting water range approach. Soil Till Res., 52:223-232, 1999.

TRUJILLO, W.; FISCHER, M.J. \& LAL, R. Roots dynamics of native savanna and introduced pastures in the Eastern Plains of Colombia. Soil Till. Res., 87:28-38, 2006.

TWERDOFF, D.A.; CHANASYK, D.S.; MAPFUMO, E.; NAETH, M.A. \& BARON, V.S. Impacts of forage grazing and cultivation on near surface relative compaction. Can. J. Soil Sci., 79:465 471, 1999. 